\title{
KAJIAN BENTUK VISUAL IKLAN (STUDI KASUS IKLAN OREO VERSI BAYANGKAN KUBERI OREO SAAT RAMADHAN)
}

\author{
Annas Marzuki Sulaiman \\ Program Studi Desain Komunikasi Visual \\ Fakultas Ilmu Komputer, Universitas Dian Nuswantoro \\ anazdesign@gmail.com
}

\begin{abstract}
Abstrak
Tujuan dari penelitian ini adalah untuk mengetahui dan menganalisis bentuk visual dalam iklan Oreo versi "Bayangkan Kuberi Oreo Saat Ramadhan" di televisi dengan menggunakan pendekatan Estetika Media Terapan. Dari analisis yang telah dilakukan berdasarkan kontekstual visual iklan yang membagi elemen gambar menjadi lima elemen yaitu: cahaya dan warna, ruang dua-dimensi, ruang tiga-dimensi, waktu/gerakan, dan suara. Iklan Oreo "Versi Bayangkan Ku Beri Oreo Saat Ramadhan" menggambarkan bahwa Oreo sebagai brand yang sangat akrab dengan konsumen, menghadirkan momen Ramadhan yang istimewa dengan saling berbagi menikmati keajaiban dan membangkitkan kembali jiwa kanak-kanak. Pada akhir iklan terdapat adegan yang menunjukkan bahwa iklan Oreo versi ramadhan bagian dari kampanye iklan global yang sudah ada yaitu "Berbagi Keajaiban". Selain itu, Iklan Oreo Versi Ramadhan ini merupakan jenis pengingat (reminder advertising), tujuannya untuk memberitahu pelanggan tentang keberadaan merek oreo yang menawarkan karakteristik dan penggunaan yang sama.
\end{abstract}

Kata Kunci: iklan, televisi, Oreo, Estetika, Ramadhan

\begin{abstract}
The purpose of this study was to determine and analyze the visual form in the Oreo ads version "Imagine Me Give Oreo During Ramadhan" on television by using the approach of Applied Media Aesthetics. From the analysis has been done based on contextual visual ads that divides the picture elements of video ads in five elements namely: light and color, the space of twodimensional, three-dimensional space, time/motion and sound. The Oreo ads version "Imagine Me Give Oreo During Ramadhan" illustrates that the Oreo as a brand is very familiar with the consumers, presenting the moment of Ramadan special by sharing experience the magic and rekindle the spirit of childhood. At the end of the ads is contained scenes show that this Ramadhan version Oreo ads is part of a global advertising campaign that already exists is "Sharing Miracles". In addition, this Ramadhan version Oreo ads is a kind reminder (reminders advertising), aim to inform customers about the existence of Oreo brand still offers characteristics, and the same usage.
\end{abstract}

Keywords: advertising, television, Oreo, Aesthetic, Ramadhan 


\section{PENDAHULUAN}

Televisi merupakan media yang efektif untuk menyampaikan iklan karena memiliki beberapa keunggulan, antara lain (1) televisi mempunyai jangkauan konsumen yang luas, jangkauan yang luas dari media televisi dapat diartikan sebagai biaya yang rendah pada tiap kali penayangan; (2) televisi mempunyai dampak yang kuat karena mampu menjangkau indera penglihatan dan pendengaran manusia sehingga kesan yang realistis karena mengkombinasikan gerakan dan suara; (3) televisi khususnya di Indonesia, diakui sebagai media iklan yang paling kuat pengaruhnya, sehingga konsumen lebih percaya pada produk yang diiklankan di televisi (Kasali : 2007).

Media televisi dapat menampilkan suara dan gambar (audio visual) secara bersamaan, sehingga memberikan kesan realistis dibandingkan dengan media iklan lainya yang hanya mampu menampilkan audio saja seperti radio maupu visual saja seperti majalah. Iklan televisi biasanya berkaitan dengan kegiatan pemasaran, sebab iklan merupakan salah satu sarana komunikasi yang efekti untuk memperkenalkan produk maupun merek suatu perusahaan. Selain untuk membangun kesadaran merek (brand awareness), iklan juga digunakan untuk memberikan informasi tentang produk dan informasi lainya, serta untuk membangun citra dan identitas (Asemah, Edegoh, dan Ogwo : 2013).

Karena keunggulan-keunggulan yang dimiliki oleh televisi, maka banyak perusahaan besar yang menggunakannya sebagai media utama untuk mempromosikan produkproduknya dengan berbagai tema kampanye yang sesuai dengan konsep pemasaranya. Salah satu produk yang gencar memelakukan kampanye iklan televisi adalah produk biskuit Oreo. Oreo adalah nama merek dagang dari PT. Mondelēz Indonesia Manufacturing (dahulu PT. Nabisco Indonesia sebelum tahun 2008 dan PT. Kraft Indonesia sebelum tahun 2013) yang berlokasi di Bekasi, Indonesia (wikipedia, 2016). Kampanye iklan televisi Oreo yang gencar dengan konsep branding yang kuat selama ini sudah berhasil menjadikan produk ini populer di masyarakat, misalnya cara makan dengan mencelupkannya ke dalam susu. Selain itu Oreo juga digunakan untuk bahan baku makanan produk merek lain, misalnya milkshake dan es krim.

Setelah sukses dengan konsep kampanye iklan "Bermain Dengan Oreo" dimana konsumen diajak bermain dengan Oreo dengan sejumlah cara unik dengan memutar, menjilati, mencelupkan, bergulir, penumpukan dan mencelupkan kedalam susu. Kini oreo meluncurkan konsep iklan iklan baru berupa kampanye Oreo dengan tema global "Berbagi Keajaiban". Kampanye Oreo tersebut memiliki sebuah misi untuk menginspirasi imajinasi dan bermain di seluruh dunia, tidak hanya dengan biskuit Oreo saja, tetapi sudah masuk dalam ranah kehidupan sehari-hari konsumen.

Pada bulan Ramadhan tahun 2016 Oreo Indonesia meluncurkan konsep iklan yang berkaitan dengan tema Ramadhan. Bulan suci Ramadan adalah momen istimewa khususnya bagi umat Islam di Indonesia yang diwarnai oleh beragam tradisi dan kebiasaan positif, misalnya dengan berbagi rejeki dengan sesama dan berbagi kebahagiaan dengan orang lain. Namun Iklan versi Ramadhan ini tidak lepas dari kampanye global yang sudah ada yaitu "Berbagi Keajaiban". Korelasi antara konsep 
iklan dengan tema Ramadhan dengan kampanye global "Berbagi Keajaiban" iklan Oreo tersebut menjadi alasan yang menarik bagi penulis untuk melakukan penelitian ini dari sisi estetisnya, untuk mengetahui bagaimana bentuk visual iklan Oreo versi "Bayangkan Ku Beri Oreo Saat Ramadhan" yang ditayangkan tahun 2016 di televisi nasional Indonesia.

\subsection{Iklan}

Menurut Kotler (2006), iklan diartikan sebagai segala bentuk penyajian non-personal tentang ide, barang, atau jasa oleh suatu sponsor tertentu yang memerlukan pembiayaan. Sedangkan menurut Kurtz (2008), Iklan adalah komunikasi nonpersonal berbayar melalui berbagai media tentang sebuah perusahaan bisnis, organisasi nirlaba, produk, atau ide oleh sponsor diidentifikasi dalam pesan yang dimaksudkan untuk menginformasikan, membujuk, atau mengingatkan anggota audiens tertentu. Jadi iklan merupakan bentuk komunikasi yang bersifat non personal atau massal dari pihak pengiklan, membutuhkan biaya tertentu dan media tertentu yang tujuanya untuk menyampaikan pesan pada audience tertentu.

Setiap iklan dipersiapkan untuk tujuan yang berbeda sesuai dengan kebutuhan, baik yang berkaitan dengan produk maupun institusi tertentu. Pengiklan menggunakan pesan iklan untuk mencapai tiga tujuan utama, yaitu untuk menginformasikan, membujuk, dan mengingatkan. Secara umum, iklan terbagi menjadi dua kategori, yaitu (1) iklan kelembagaan (Institutional advertising), adalah iklan yang mempromosikan konsep, ide, filosofi, atau niat baik suatu industri, perusahaan, organisasi, orang, lokasi geografis, atau instansi pemerintah (Kurtz, 2008). Jenis iklan ini tidak hanya memiliki manfaat sosial, tetapi juga membantu untuk membangun citra organisasi; dan (2) iklan produk (product advertising) adalah iklan yang berisi penjualan nonpersonal dari barang atau jasa tertentu, merupakan jenis iklan yang paling sering digunakan dalam kegiatan promosi (Pride dan Ferrell, 2009).

Menurut Pride dan Ferrell (2009), berdasarkan tujuanya iklan produk terdiri dari empat macam, yaitu (1) Iklan perintis (pioneer advertising), tujuanya untuk merangsang permintaan produk (bukan merek tertentu) dengan menginformasikan pelanggan potensial tentang fitur, kegunaan, dan manfaat produk, jenis iklan ini digunakan bila produk berada dalam tahap perkenalan produk; (2) iklan kompetitif (competitive advertising) atau iklan persuasif, tujuannya untuk mendorong permintaan terhadap merek tertentu dengan mempromosikan fitur merek, penggunaan, keuntungan, dan untuk membuat perbandingan produk secara langsung maupun tidak langsung; (3) iklan pengingat (reminder advertising), iklan pengingat tujuannya untuk memberitahu pelanggan tentang keberadaan merek tertentu yang masih di sekitar dan masih menawarkan karakteristik, penggunaan, dan keuntungan tertentu; (4) iklan penguatan (reinforcement advertising), tujuanya untuk menjamin pengguna saat ini, bahwa mereka telah memilih merek yang tepat dan memberitahu mereka bagaimana mendapatkan kepuasan maksimal dari merek tersebut. 


\subsection{Penelitian terkait yang pernah dilakukan}

Kajian yang berkaitan dengan bentuk iklan televisi di Indonesia masih belum banyak dilakukan. Ezekiel, Leo, dan Comfort (2013) mengkaji pemanfaatan estetika pada iklan televisi. Makalah ini menyimpulkan bahwa iklan televisi memerlukan elemen estetika untuk menarik pemirsa. Makalah ini merekomendasikan, antara lain bahwa, pengiklan harus berusaha untuk membuat penonton memiliki pengalaman estetik dalam produk atau jasa yang diiklankan dan bahwa ada kebutuhan untuk produk dan layanan terusmenerus diiklankan sehingga membuat konsumen menjadi setia kepada produk dan layanan tersebut.

Sulaiman dan Murtana (2015) dalam kajianya terhadap Iklan Televisi Kuku Bima Energi yang dianalisis dengan teori estetika Monroe C. Beardsley. Hasil penelitian menunjukkan bahwa Kuku Bima Energi dalam pencitraannya telah berhasil menggunakan isu nasionalisme untuk mengikat konsumen dengan nilai-nilai budaya dan pariwisata, menciptakan citra nasionalis dan cinta terhadap budaya lokal yang dikaitkan dengan merek Kuku Bima Energi.

\section{METODE PENELITIAN}

Metodologi penelitian yang digunakan dalam penelitian ini adalah metode penelitian kualitatif yang hasilnya diskriftif dalam bentuk narasi yang rinci dan mendalam, agar mudah dipahami dan bisa mengarahkan secara lebih jelas dan rinci pada saran operasional sebagai usaha perbaikan, dan juga dalam menentukan bentuk tindakan kebijakan (Sutopo, 2006) sehingga jenis penelitian ini sangat sesuai untuk meneliti bidang ilmu sosial budaya. Pendekatan yang digunakan adalah Estetika Media Terapan (Applied Media Aestetic) oleh Herbert Zettl. Zettl (2014) memperkenalkan sebuah konsep Estetika baru yang khusus untuk menganalisis karya seni berupa audio visual yang dikenal dengan Estetika Media Terapan (Applied Media Aestetic) yang berbeda dengan estetika tradisional. Fokus perhatian dari konsep estetika terapan terutama berkaitan dengan sejumlah fenomena estetika, yang secara kontekstual membagi elemen gambar dari tampilan audio visual yaitu: cahaya dan warna, ruang duadimensi, ruang tiga-dimensi, waktu/gerakan, dan suara, yang berdampak pada reaksi persepsi audiens kepada fenomena estetis yang ada, bukan menitik beratkan pada keindahan dan filsafat seni.

Peneliti akan mengkaji studi kasus iklan televisi Oreo Versi Bayangkan Ku Beri Oreo Saat Ramadhan yang diluncurkan pada tahun 2016 yang dilakukan dengan metode deskriptif-analitis untuk pengkorelasian, mengakumulasi informasi mengenai pencitraan merek Oreo, latar belakang, konsep dan strategi komunikasi visual iklan. Teknik pengumpulan data dilakukan dengan menggunakan studi dokumentasi dengan melihat rekaman iklan Oreo yang di download dari Youtube dan studi pustaka yang berkaitan dengan permasalahan mengenai periklanan.

\section{PEMBAHASAN}

Untuk mengkaji iklan televisi Oreo versi "Bayangkan Ku Beri Oreo Saat Ramadhan" digunakan metode analisis Estetika Media Terapan (Applied Media Aestetic) yang dikemukakan oleh Herbert Zettl. Teori Estetika Media Terapan merupakan sebuah 
kajian bentuk iklan yang ditujukan khusus untuk media televisi dan film untuk menjelaskan bagaimana elemen-elemen desain dapat terstruktur dan diterapkan untuk menghasilkan gambar visual dan suara secara maksimal efektif dalam video dan film. Teori Estetika ini secara kontekstual membagi elemen gambar dari video dan film yang terdiri dari: (1) cahaya dan warna, (2) ruang dua-dimensi, (3) ruang tiga-dimensi, (4) waktu/gerakan (ruang ruang empat-dimensi), dan (5) suara.

Sebelum dilakukan analisis pada iklan Oreo, dilakukan pemilihan pada scene yang dianggap mewakili keseluruhan iklan. Masing-masing scene tersebut kemudian diidentifikasi untuk mengetahui bentuk iklan melalui elemen-elemen visual pembentuk iklan. Berikut adalah analisis iklan iklan televisi Oreo versi "Bayangkan Ku Beri Oreo Saat Ramadhan" digunakan metode analisis Estetika Media Terapan (Applied Media Aestetic) yang dikemukakan oleh Herbert Zettl.

Tabel 1. Urutan Iklan Oreo Versi Ramadhan 2016

\begin{tabular}{|c|c|}
\hline Visual Iklan & Keterangan \\
\hline & $\begin{array}{l}\text { Adegan } 1 \\
\text { Beberapa orang anggota keluarga yang terdiri dari seorang laki- } \\
\text { laki paruh baya memakai baju muslim warna krem dengan kopiah } \\
\text { hitam, perempuan paruh baya dengan pakain kasual berwarna } \\
\text { merah muda, seorang laki-laki muda memakai baju muslim } \\
\text { berwarna hijau muda dengan kopiah hitam, perempuan muda } \\
\text { dengan pakaian muslim berwarna oranye memakai jibab krem, } \\
\text { serta seorang anak laki-laki dan perempuan sedang } \\
\text { bercengkerama menghadap hidangan buka puasa pada sebuah } \\
\text { meja dihalaman sebuah rumah dengan sebungkus biskuit Oreo. } \\
\text { Laki-laki kemudian muda memegang bungkusan Oreo sambil } \\
\text { melihat di kejauhan. } \\
\text { Cahaya dan warna: pencahayaan datar didominasi oleh warna- } \\
\text { warna hangat, nuansa suasana lingkungan berwarna cenderung } \\
\text { oranye } \\
\text { Ruang dua-dimensi: Aspek rasio layar } 1,78: \text { Kamera: MS } \\
\text { menampilkan banyak obyek dalam satu adegan, posisi kamera } \\
\text { sejajar dengan bidang horisontal menggunakan keseimbangan } \\
\text { statis menekankan stabilitas, dan terlihat statis (105) } \\
\text { Ruang tiga-dimensi: Obyek yang menutupi obyek lainya, serta } \\
\text { ketajaman fokus dapat menunjukkan kedalaman, pada adegan ini } \\
\text { terlihat posisi tiga gelas yang ada di meja berada paling depan, } \\
\text { laki-laki berbaju hijau berada paling belakang, dengan background } \\
\text { rumah. Namun kamera difokuskan pada obyek manusia dan oreo. } \\
\text { Waktu/gerakan : } 2 \text { detik/Kamera bergerak menuju ke arah obyek } \\
\text { Suara: musik jingle oreo }\end{array}$ \\
\hline & $\begin{array}{l}\text { Adegan } 2 \\
\text { Nampak Ekspresi wajah Laki-laki muda berkopiah yang } \\
\text { memandang di kejauhan sambil tersenyum tampak sedang } \\
\text { memikirkan sesuatu. } \\
\text { Cahaya dan warna: pencahayaan datar, nuansa suasana } \\
\text { lingkungan berwarna cenderung oranye } \\
\text { Ruang dua-dimensi: Kamera: CU } \\
\text { Ruang tiga-dimensi: Manipulasi kedalaman dengan }\end{array}$ \\
\hline
\end{tabular}




\begin{tabular}{|c|c|}
\hline Visual Iklan & Keterangan \\
\hline & $\begin{array}{l}\text { memanfaatkan selektif fokus, yaitu fokus hanya pada area spesifik } \\
\text { sepanjang sumbu z (wajah) terlihat lebih jelas dan dekat, obyek } \\
\text { yang tidak fokus akan kelihatan kabur (rumah) terlihat lebih jauh. } \\
\text { Teknik dalam degan ini bertujuan untuk mempertegas ekspresi } \\
\text { wajah. } \\
\text { Waktu/gerakan : } 1 \text { detik/kamera berputar ke arah kanan } \\
\text { Suara: Musik Jingle Oreo } \\
\quad \text { Lirik lagu "Bayangkan ku..." }\end{array}$ \\
\hline & $\begin{array}{l}\text { Adegan } 3 \\
\text { Seorang pegawai pos yang memakai seragam warna oranye } \\
\text { terlihat murung sedang mengantarkan surat dengan latar } \\
\text { belakang perumahan di sore hari. } \\
\text { Cahaya dan warna: pencahayaan datar didominasi oleh warna- } \\
\text { warna hangat, nuansa suasana lingkungan berwarna cenderung } \\
\text { oranye } \\
\text { Ruang dua-dimensi: Kamera: MS menunjukkan orang yang berdiri } \\
\text { di sebelah kiri, posisi kamera sejajar dengan bidang horisontal, } \\
\text { obyek berada di sebelah kiri sehingga terdapat ruang kosong yang } \\
\text { luas di sebelah kanan. ruang kosong diisi Latar belakang rumah } \\
\text { yang diambil menyudut sehingga terlihat dinamis } \\
\text { Ruang tiga-dimensi: } \\
\text { Waktu/gerakan : } 1 \text { detik/obyek bergerak ke arah kamera } \\
\text { Suara: musik jingle oreo }\end{array}$ \\
\hline & $\begin{array}{l}\text { Adegan } 4 \\
\text { Laki-laki berkopiah memberikan sebungkus Oreo kepada petugas } \\
\text { pos dengan tersenyum. } \\
\text { Cahaya dan warna: pencahayaan datar didominasi oleh warna- } \\
\text { warna hangat, nuansa suasana lingkungan berwarna cenderung } \\
\text { oranye, kemasan Oreo berwarna biru (warna dingin) terlihat } \\
\text { kontras diantara warna-warna hangat } \\
\text { Ruang dua-dimensi: Kamera: MS menunjukkan orang yang berdiri } \\
\text { atau saling berhadapan-hadapan, posisi kamera sejajar dengan } \\
\text { bidang horisontal } \\
\text { Ruang tiga-dimensi: manipulasi kedalaman perspektif dengan } \\
\text { memanfaatkan selektif fokus, yaitu fokus terlihat pada obyek oreo } \\
\text { untuk mempertegas keberadaan produk } \\
\text { Waktu/gerakan : } 1 \text { detik/obyek mendekat ke arah kamera } \\
\text { Suara: Musik Jingle Oreo } \\
\quad \text { Lirik lagu “Beri Oreo...” }\end{array}$ \\
\hline & $\begin{array}{l}\text { Adegan } 5 \\
\text { Petugas Pos tersenyum memandang di kejauhan sambil } \\
\text { memegang Oreo tampak sedang memikirkan sesuatu. } \\
\text { Cahaya dan warna: pencahayaan datar didominasi oleh warna- } \\
\text { warna hangat, nuansa suasana lingkungan berwarna cenderung } \\
\text { oranye, kemasan Oreo berwarna biru (warna dingin) terlihat } \\
\text { kontras diantara warna-warna hangat } \\
\text { Ruang dua-dimensi: Kamera: MCU } \\
\text { Ruang tiga-dimensi: Manipulasi kedalaman perspektif dengan } \\
\text { memanfaatkan perbedaan kedudukan obyek dan selektif fokus, } \\
\text { yaitu fokus terlihat pada obyek tukang pos yang memegang oreo } \\
\text { dan terlihat di depan untuk mempertegas ekspresi wajah dan }\end{array}$ \\
\hline
\end{tabular}




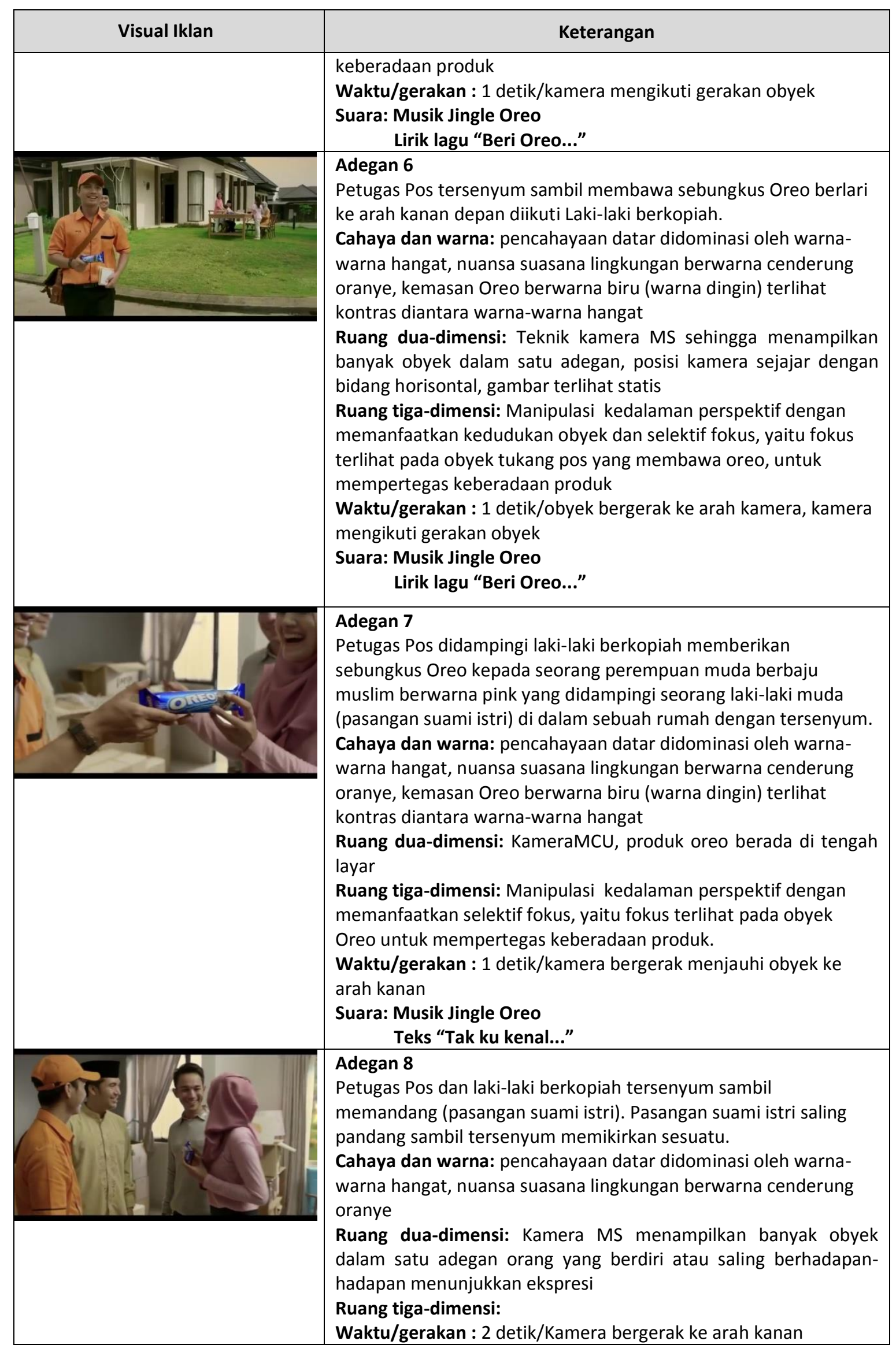




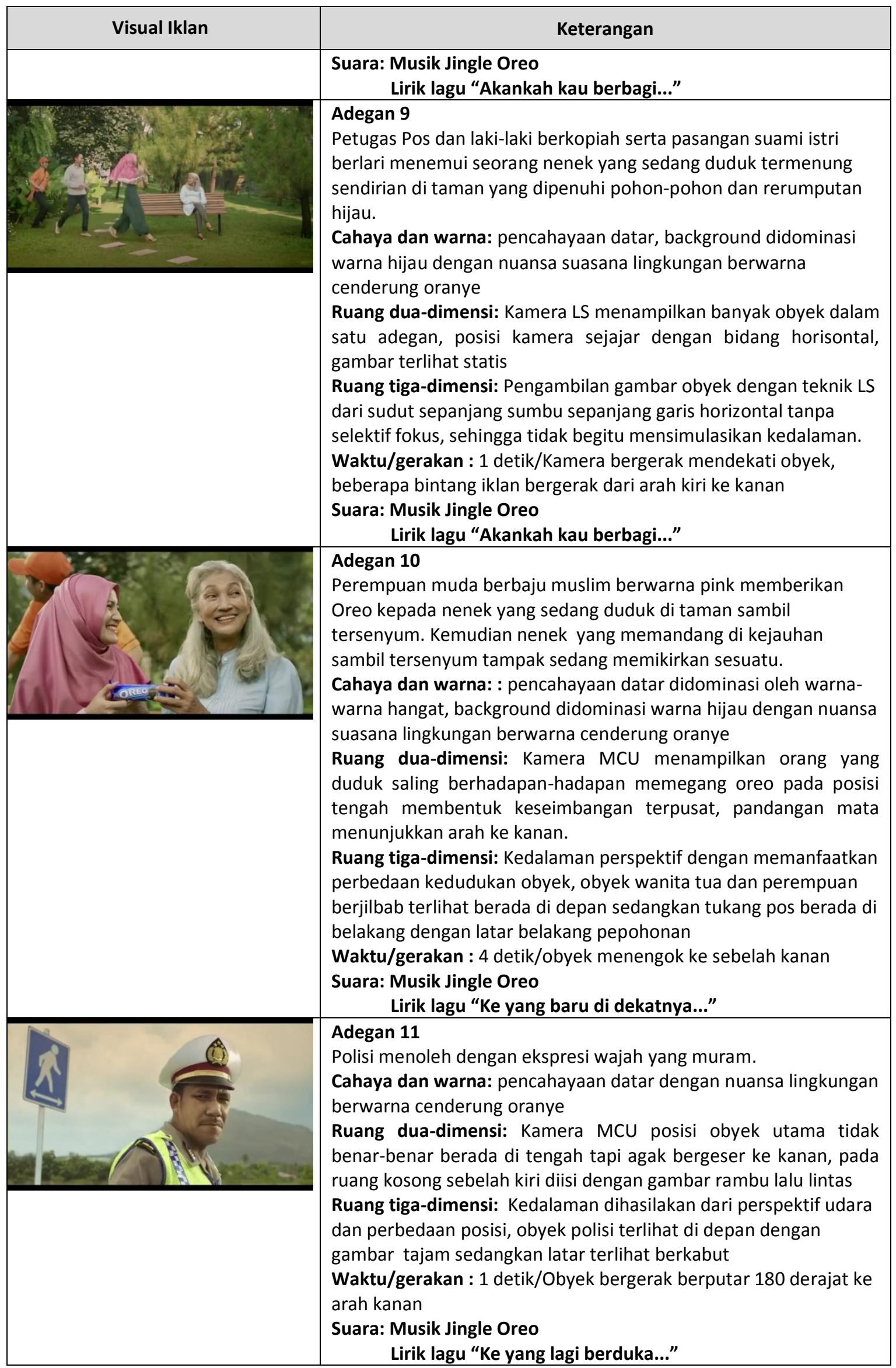




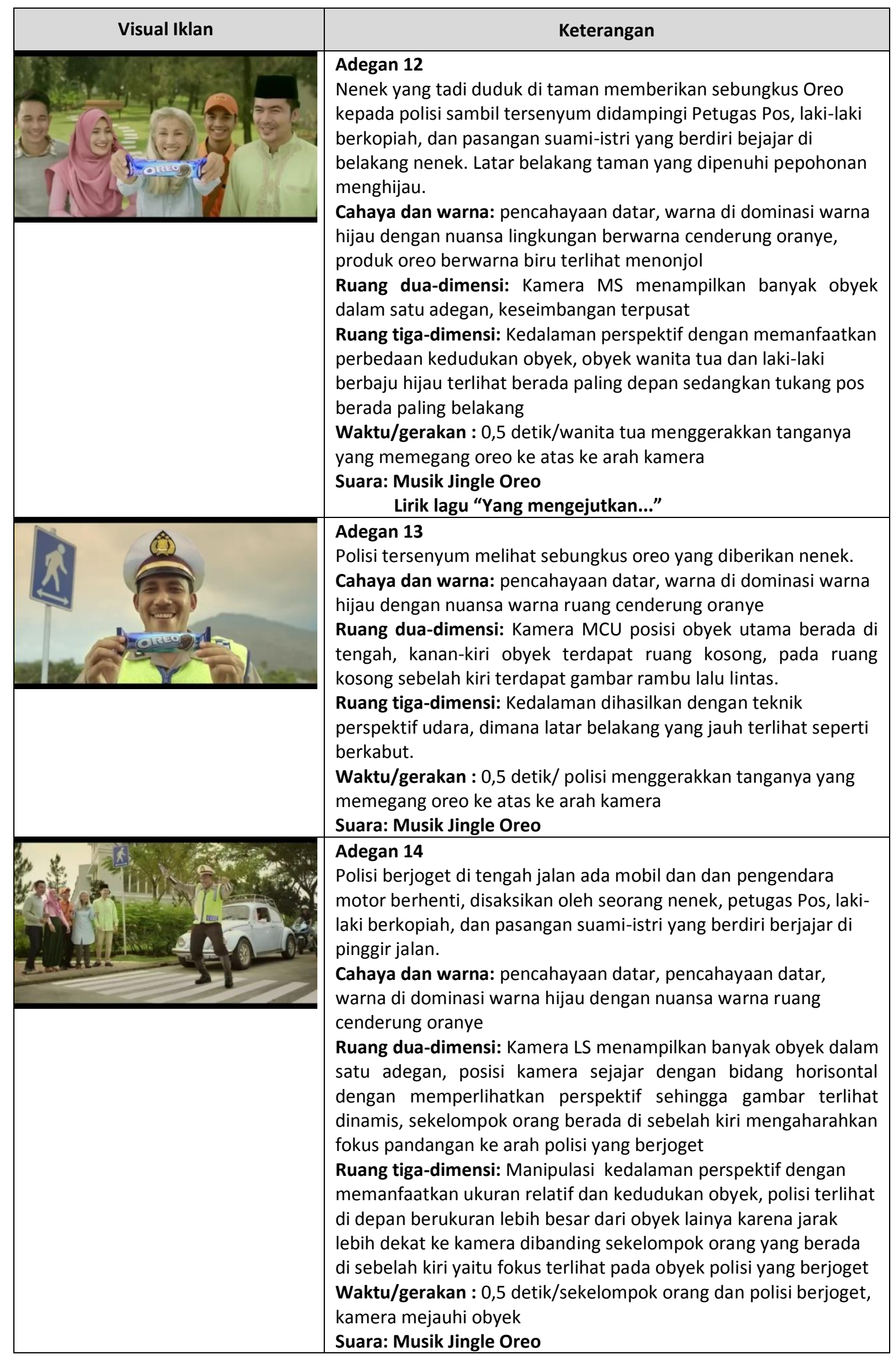




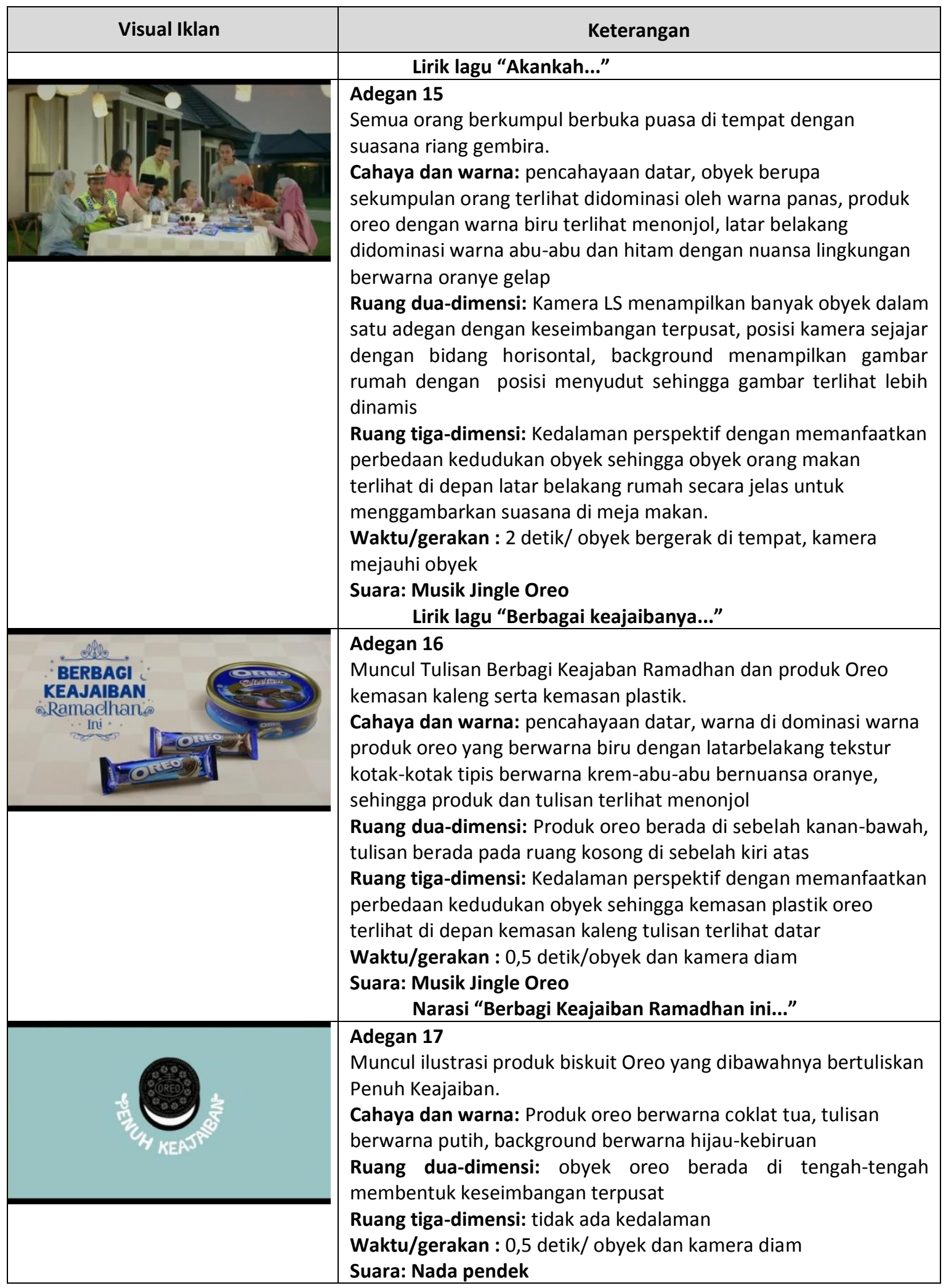

\section{Keterangan teknik pengambilan gambar}

Long Shot (LS) : yaitu pengambilan secara keseluruhan. Gambar diambil dari jarak jauh, seluruh objek terkena hingga latar belakang objek. 
Medium Shot (MS) : yaitu pengambilan dari jarak sedang, jika objeknya orang maka yang terlihat hanya separuh badannya saja (dari perut/pinggang keatas).

Medium Close-Up (MCU): yaitu hampir sama dengan MS, jika objeknya orang dan diambil dari dada keatas.

Close Up (CU) : yaitu gambar diambil dari jarak dekat, hanya sebagian dari objek yang terlihat seperti hanya mukanya saja.

\section{Analisis Estetika Media Terapan (Applied Media Aestetic)}

a) Elemen 1, Cahaya dan Warna:

\section{Cahaya dan Bayangan}

Pencahan pada seluruh dalam iklan ini memiliki teknik yang sama, pencahayaan pada para aktor dan biskuit Oreo sebagai obyek utama serta background menggunakan pencahayaan datar, Yaitu menggunakan cahaya yang tampaknya datang dari segala arah, sehingga bayangan terlihat sangat tipis dan hampir tidak ada. Pencahayaan datar tidak mengungkapkan sumber cahaya tertentu Kecuali untuk backlight yang kuat, Meskipun pencahayaan datar sering dilakukan untuk visibilitas atau kemanfaatan yang optimal, namun dapat memenuhi beberapa fungsi estetika penting. Pencahayaan datar sangat ideal untuk tindakan yang berkelanjutan, sehingga memungkinkan kamera untuk mengambil gambar dari berbagai sudut tanpa harus khawatir tentang bayangan yang mengganggu, dan dengan demikian memberi mobilitas maksimum kepada para bintang iklan. Pencahayaan datar dapat menyarankan efisiensi, kebersihan, kebenaran, menyenangkan, dan suasana hati yang optimis. Dalam pencahayaan datar, fungsi tematik dan emosional begitu terjalin dengan baik.

\section{Warna}

Warna dapat menunjukkan suasana, selain itu warna juga dapat membuat satu obyek lebih menojolkan dari obyek yang lain. Dalam iklan Oreo ini didominasi oleh warna-warna hangat seperti oranye, dan merah muda (misalnya pakaian yang dikenakan para bintang iklan dan background dengan nuansa suasana lingkungan berwarna cenderung oranye. Kemasan Oreo yang berwarna biru (warna dingin) terlihat kontras diantara warna-warna hangat yang mendominasi di sekitarnya. Warna-warna hangat merupakan warna yang memiliki energi tinggi, dapat mengkomunikasikan perasaan kehangatan dan kasih sayang. Warna hangat dalam iklan Oreo ini didominasi oleh warna seperti oranye, dan merah muda (misalnya pakaian yang dikenakan para bintang iklan dan background dengan nuansa suasana lingkungan berwarna cenderung oranye. Backgroun suasana perumahan dengan langit berwarna oranye ke abu-abuan menunjukkan suasana dan waktu di sore hari menjelang berbuka puasa. Pada akhir terlihat langit yang sudah semakin gelap dan nampak lapu diatas meja dinyalakan menunjukkan waktu maghrib saat berbuka puasa (Adegan 15). 


\section{b) Elemen 2, bidang dua dimensi:}

\section{Area}

Aspek rasio layar yang digunakan dalam iklan Oreo ini adalah aspek layar HDTV dengan ukuran $16 \times 9$, atau 1,78: 1, membuat layar ini lebih membentang horizontal dari layar televisi tradisional. Rasio aspek HDTV dapat menampung format film layar lebar tanpa kehilangan gambar yang jatu di sisi kanan kirinya. Ketika membingkai gambar satu obyek dengan teknik Medium Shot (MS), Medium Close Up (MCU), dan Close Up (CU), ada banyak ruang kosong yang tidak digunakan di kedua sisi layar (disebut zona mati). Teknik pengambilan gambar MS ini muncul pada adegan 3 dan 6, CU pada adegan 5, 11, dan 13 namun pada iklan oreo ini ruang kosong tersebut disiasati dengan memberikan Latar belakang rumah yang diambil menyudut (Adegan 3 dan 5) sedangkan pada adegan 11, 12 dan 13 posisi polisi tidak benar-benar berada di tengah tapi agak bergeser ke kanan, pada ruang kosong sebelah kiri diisi dengan gambar rambu lalu lintas sehingga terbentuk keseimbangan. Aspek layar HDTV cocok untuk menunjukkan area yang lebih luas secara horizontal sehingga akan menampilkan lebih banyak obyek dalam satu adegan yang menunjukkan suasana kehangatan dan keceriaan (Adegan 1, 3, 6, 12, 14, dan 15) dan lebih mudah untuk menunjukkan orang-orang yang berdiri atau duduk berkumpul atau berhadapan dalam percakapan (Adegan 4, 8, 9, dan 10).

\section{Kekuatan Dalam Layar}

Pada setiap adegan dalam iklan ini terdapat keseimbangan kekuatan massa grafis dan daya tarik dari frame dalam layar. Berat gambar ditentukan dengan dimensi objek (berapa banyak daerah objek relatif terhadap Total layar area), bentuk dan orientasi dasar, lokasinya di dalam bingkai, dan warnanya. Untuk menonjolkan produk yang ditawarkan, pada iklan ini banyak adegan yang menampilkan Oreo pada posisi tengah namun agak ke bawah layar sehingga keseimbangan terlihat lebih dinamis (lihat adegan 4,5,7,10, 12, dan 13). Keseimbangan dinamis juga digunakan untuk menampilkan perubahan ekspresi wajah sebelum (tampak muram, tidak bahagia) dan sesudah menerima pemberian Oreo (tampak ceria dan bahagia) (adegan 2, 5, 11, dan 12). Arah obyek suatu objek dan pandangan mata atau arah wajah juga bisa menambah kekuatan berat massa objek, dalam gambar Adegan 4, 5, 7, 10, 12, dan 13 terlihat para bintang iklan memegang dan mengarahkan pandanga mata ke Oreo, sehingga menambah kekuatan visual dan menonolkan produk Oreo.

\section{c) Elemen 3, bidang tiga dimensi: Kedalaman dan Volume}

Kedalaman tiga dimensi dalam iklan ini ditunjukkan dengan adanya perbedaan ukuran atau volume secara kontas seperti yang terlihat pada Adegan 4, 6, dan 14. Obyek yang terletak dekat dengan kamera mempunyai ukuran relatif besar, sedangkan objek serupa yang diposisikan lebih jauh pada sumbu z maka ukuran gambar secara dramatis berkurang. Pada Adegan 4 dan 7 dimunculkan manipulasi kedalaman perspektif aerial dengan memanfaatkan selektif fokus, yaitu, fokus hanya pada area spesifik sepanjang sumbu z obyek yang tidak fokus akan kelihatan 
kabur. Pembentukan kedalaman ruang tiga demensi dalam iklan ini juga ditunjukkan dengan adanya gerakan ke arah kamera sepanjang sumbu z seperti yang terlihat pada gerakan petugas pos dan laki-laki perkopiah kearah kamera seperti pada adegan 6 .

\section{d) Elemen 4, waktu /gerakan:}

\section{Waktu}

Iklan Oreo ini berdurasi total 30 detik, masing-masing adegan berdurasi setengah detik sampai dengan empat detik. Durasi waktu terpanjang pada adegan 10 yaitu selama empat detik. Keseluruhan adegan tersebut dari awal sapai akhir menunjukkan waktu selama menjelang berbuka puasa sampai dengan waktu maghrib atau waktu berbuka puasa yang ditunjukkan dengan adegan 15 saat adegan berbuka puasa bersama.

\section{Gerakan}

Gerakan-gerakan pada keseluruhan adegan iklan ini terdiri dari gerakan kamera dan gerakan obyek. Keseluruhan gerakan yang ditampilkan dalam setiap adegan menunjukkan gerakan nomal sebagian besar menunjukkan arah ke kanan yang ditunjukkan oleh adegan 6 dan 9 berupa gerakan obyek (bintang iklan) ke arah kanan dan gerakan kamera ke arah kanan (Adegan 7 dan 8). Gerakan yang sama pada beberapa adegan tersebut dapat menunjukkan persepsi kebersambungan antar adegan yang dapat menyusun kebersambungan keseluruhan cerita dari awal sampai dengan akhir adegan. Kemudian pada adegan 16 Muncul Tulisan Berbagi Keajaban Ramadhan disertai kemunculan visual produk Oreo kemasan kaleng serta kemasan plastik, dengan background berwarna krem-abu-abu dilanjutkan adegan 17 Muncul ilustrasi produk biskuit Oreo yang dibawahnya bertuliskan Penuh Keajaiban Dengan background berwarna hijau-kebiruan yang identik dengan iklan versi sebelumnya yaitu Iklan Oreo Penuh Keajaiban Versi Hiu \& Vampire, menunjukkan bahwa iklan Oreo versi ramadhan ini masih bagian dari kampanye iklan global yang sudah ada yaitu "Berbagi Keajaiban".

\section{e) Elemen 5, Suara:}

Semua adegan iklan ini dari awal sampai akhir (adegan 1-16) diisi dengan suara jinggle lagu berbagi keajaiban Oreo. Pada Adegan 16 terdapat narasi suara seorang pria yang berbunyi "berbagi keajaiban Ramadhan ini"

\section{KESIMPULAN \& SARAN}

\subsection{Kesimpulan}

Berdasarkan hasil analisis Estetika Media Terapan (Applied Media Aestetic) terhadap iklan televisi oreo versi "Bayangkan Ku Beri Oreo Saat Ramadhan" yang ditayangkan tahun 2016 dapat disimpulkan bahwa iklan ini berusaha menunjukkan keberadaan produk oreo pada pada momen lebaran yang menjadi tradisi bangsa Indonesia. Produk Oreo ditampilkan secara menonjol dengan pengaturan posisi, fokus dan ukuran dalam tiap adegan sehingga menarik perhatian audiens. Produk Oreo juga ditonjolkan dengan pengaturan kekontrasan warna, oreo yang 
berwarna dingin (biru) dipadukan dengan warna-warna hangat sebagai warna dominan seperti merah muda dan oranye yang ada di sekitarnya, sehingga warna biru akan terlihat menonjol. Dengan pengaturan posisi, fokus, ukuran dan warna, Iklan ini juga berusaha menonjolkan ekspresi wajah dan tingkah laku dari para bintang iklan sebelum dan sesudah mendapatkan produk Oreo. Dipadukan dengan gerakan-gerakan kamera yang aktif, iklan ini bisa menggambarkan suasana kehangatan keceriaan dan kedinamisan.

\subsection{Saran}

Penelitian kualitatif interpretatif terhadap iklan Oreo versi "Bayangkan Kuberi Oreo Saat Ramadhan" di televisi dengan pendekatan estetika media terapan, digunakan untuk menganalisa bentuk visual iklan yang menitik beratkan pada reaksi persepsi audiens. Iklan ini masih bisa dianalisis dengan menggunakan beberapa pendekatan estetika lainya yang menitik beratkan pada keindahan dan filsafat seni, sehingga akan menghasilkan interpretasi yang berbeda yang dapat memperkaya reverensi sudah ada.

\section{DAFTAR PUSTAKA}

Asemah, Ezekiel S., Edegoh, Leo O.N. dan Ogwo, Comfort A.. 2013. Utilisation Of Aesthetics In Television Advertising. Asian Journal Of Socialsciences And Humanities, Vol 2 No2

Kasali, Rhenald. 2007. Manajemen Periklanan, Konsep dan Aplikasinya di Indonesia. Jakarta: Pustaka Utama Grafiti. 121-122

Kothler, Philip. 2006. Marketing management. New Jersey: Pearson Education. 544

Kurtz, David L. 2008. Contemporary Marketing. Mason: South-Western. 527

Paul, Copley. 2004. Marketing Communications Management: Concepts And Theories, Cases And Practices. Burlington: Elsevier.

Pride, William M. dan Ferrell, O. C. 2009. Foundations Of Marketing. Boston: Houghton Mifflin Company. 423

Sulaiman, Annas Marzuki, dan Murtana, I Nyoman. 2015. Strategi Visual Iklan Televisi Kuku Bima Energi Produksi Pt. Sido Muncul Semarang. Gelar, vol 3, no 1: UPT Penerbitan ISI Surakarta. 80-89

Sutopo, H.B. 2006. Metodologi penelitian kualitatif: dasar teori dan terapannya dalam penelitian. Surakarta: Sebelas Maret University Press. 41

Wikipedia. 2016. https://id.wikipedia.org/wiki/Oreo diakses pada tanggal 8 Agustus 2016.

Zettl, Herbert. 2014. Sight Sound Motion: Applied Media Aesthetics, Boston: Cengage Learning. 3-4 